\title{
VIDA ETERNA A SERVIÇO DA PÁTRIA Mausoléus Militares em Cemitérios Brasileiros (1924-1982)
}

\author{
ETERNAL LIFE IN SERVICE OF THE HOMELAND \\ Military Mausoleums in Brazilian Cemeteries (1924-1982)
}

\section{Adriane Piovezan ${ }^{1}$}

dricapiovezan@gmail.com

\section{RESUMO}

Com o fim da Primeira Guerra Mundial as homenagens aos mortos em combate sofreram transformações significativas em relação as atitudes diante da morte em guerra. A substituição do monumento aos heróis pelos mausoléus coletivos foi um dos aspectos mais significativos dessa mudança. O Cemitério São João Batista localizado na cidade do Rio de Janeiro possui exemplos dessas práticas funerárias em que a instituição, no caso as Forças Armadas, tornam-se gestoras da rememoração desses indivíduos. No presente artigo a questão da memória institucional presentes nesses mausoléus militares são problematizadas.

Palavras-chave: Cemitérios, mausoléus, Instituições Militares.

${ }^{1}$ Centro UNIBEM, Curitiba. 


\begin{abstract}
With the end of World War I, the tributes to the dead in combat underwent significant transformations in relation to attitudes towards death at war. The replacement of the monument to the heroes by the collective mausoleums was one of the most significant aspects of this change. The São João Batista Cemetery located in the city of Rio de Janeiro has examples of these funerary practices in which the institution, in this case the Armed Forces, become managers of the rememoration of these individuals. In the present article the question of the institutional memory present in these military mausoleums is problematized.
\end{abstract}

Keywords: Cemetery, mausoleums, Military Institutions.

\title{
MORTE E MEMÓRIA
}

Os Monumentos, mausoléus e comemorações compõem uma parte das funções sociais da memória em que o principal desafio é estabelecer sentimentos de pertencimento e continuidade. Para o historiador alemão Jörn Rüsen existem três níveis de memória: a memória comunicativa, a memória coletiva e a memória cultural. Estes níveis mudam ao longo do tempo, variando principalmente de acordo com o grau de institucionalização da memória. Em sua distinção, ele afirma:

[...] a memória cultural é a matéria para rituais e atuações altamente institucionalizadas. Ela tem o seu próprio meio e um lugar fixo na vida cultural de um grupo. A memória cultural representa o sistema político como uma estrutura una, bem como sua permanência no fluxo temporal dos eventos políticos. (RÜSEN, 2009, p.167) 
No contexto brasileiro, percebe-se a tentativa de construção de um culto cívico dos mortos a partir da criação de mausoléus fúnebres militares coletivos. No entanto, esta memória dos caídos em combate pela Pátria se tornou ao longo dos anos uma memória institucionalizada em que as Forças Armadas reforçam sua posição e a homenagem aos mortos passa a ser homenagem à instituição.

A ideia central do morto enquanto pertencente ao grupo aparece em monumentos fúnebres como o Mausoléu aos Mortos do Movimento Tenentista localizado no Cemitério São João Batista no Rio de Janeiro (RJ), de 1924; no mesmo cemitério o Mausoléu aos Mortos da Divisão Naval em Operações de Guerra (DNOG) na Primeira Guerra Mundial, construído em 1928; o Mausoléu dos Mortos na Intentona Comunista de 1935, hoje localizado na Praia Vermelha no Rio de Janeiro (RJ) mas que originalmente foi construído no cemitério. Também o Mausoléu dos mortos na Intentona Integralista de 1938, os dois Mausoléus dos Aviadores, um de 1941 e o outro de 1957, e o Mausoléu da FEB (Força Expedicionária Brasileira) de 1980.

Tais construções têm por objetivo rememorar os eventos em que esses soldados foram perdidos por meio de uma narrativa que privilegie uma história oficial da instituição.

Koselleck comparou os monumentos fúnebres na Alemanha, França e Itália e entendeu que nesses locais ocorreu a tentativa de se constituir uma lição de moral 
e civismo dada pelos mortos, a partir de seus túmulos. Neste sentido, o autor problematiza de que forma os monumentos aos mortos funcionam mais como meio de atender os interesses dos vivos do que realmente homenagear os mortos. (Koselleck, 1992)

Entretanto, essa não é a única motivação para a construção de tais monumentos. Van Creveld, historiador radicado nos EUA, identifica três fases distintas dos monumentos fúnebres de guerra. Em uma primeira fase da História Humana, que se estende até o século XIX, os monumentos celebravam a vitória nas batalhas, o heroísmo dos guerreiros que a tornaram possível e a exaltação patriótica. Numa segunda fase, já durante a Primeira Guerra Mundial, os monumentos celebram os soldados como vítimas do sacrifício pelo bem comum. A última etapa da história desses monumentos corresponde à época contemporânea, no qual não se comemora nem as batalhas nem os soldados mortos, mas se protesta contra a violência da guerra e se prega o pacifismo. (Creveld, 2008, p.244)

\section{CEMITÉRIOS DE GUERRA}

Em pleno século XXI, a discussão de como preservar os restos mortais de indivíduos que morreram pela pátria apontam para a problematização das transformações culturais ao longo do tempo sobre o tema. A memória desses eventos é profundamente marcada pela disputa. Confrontos entre algozes e vítimas, opressão e vingança surgem na rememoração desses eventos. 
O exame da historiografia internacional revela como são vastas e complexas as tarefas afetas à identificação, sepultamento e translado dos mortos em guerras estrangeiras. Geralmente comissões de repatriamento de restos mortais são formadas muitos anos depois de terminado o conflito.

No que se refere à estética, a questão do local de sepultamento dos mortos em guerra foi elaborada inicialmente pelos estadunidenses e em seguida emulada pelos europeus. O estilo escolhido foi o que privilegiava os cemitérios rurais, ou o chamado The park movement of cemiteries ${ }^{2}$.

Cabe comentar esse modelo de sepultura por eles adotado. A lápide é harmonizada com a paisagem natural, com gramas e árvores. A paisagem remete ao sentimento patriótico relacionado com o poder moral da natureza que regenera, ao mesmo tempo em que rejeita a pompa do estilo dos cemitérios românticos, como o Père Lachaise ${ }^{3}$.

Ao mesmo tempo em que esses cemitérios militares seguem essa tendência de padronização de sepulturas, manifestam-se variados tipos de monumentos. Alguns são erigidos em memória dos mortos que não foram identificados. Desde o princípio pretendia-se que passassem a simbolizar os mortos na guerra além-mar.

\footnotetext{
${ }^{2}$ A expressão já surge entre 1830 e 1850 nos Estados Unidos, para esse tema ver MOSSE, G. Fallen Soldier.

${ }^{3}$ Sobre esse tema ver CATROGA, Fernando. O Céu da memória: Cemitério Romântico e Culto Cívico aos Mortos. Coimbra: Minerva, 1999.
} 
Para ilustrar essa vertente, diversos retornos simbólicos à pátria dos mortos ocorreram. Tratavam-se de grandes e significativos eventos públicos, materializados na inauguração de sucessivos monumentos dedicados ao soldado desconhecido. Esse processo começou em 1920, com o enterramento de soldados desconhecidos na Abadia de Westminster em Londres; sob o Arco do Triunfo em Paris; e assim sucessivamente nos EUA, Itália, Bélgica, Portugal, Alemanha, etc. $\mathrm{O}$ aspecto comum a todos esses ritos, independentemente do país, era que desta forma que todos os soldados desconhecidos mortos nas guerras seriam homenageados.

O simbolismo atuava como substituto de um real translado e reenterramento para todos aqueles impossibilitados de realizá-lo na prática. De todos os ícones o mais forte era o cenotáfio, um túmulo simbólico, representando todos os mortos em determinada época ou conflito. O caso extremo é o do cenotáfio de Londres. $\mathrm{Na}$ origem se tratava de um monumento na forma de um mero túmulo estilizado, de caráter provisório, construído no centro de Londres meramente para marcar a passagem do desfile da vitória na Primeira Guerra Mundial em 1919. Porém, quase imediatamente, converteu-se em um polo de atração para multidões.

Esses esforços em enterrar ou reenterrar os caídos, as obras erguidas em sua homenagem, as manifestações públicas de luto e rememoração dos mortos são influenciadas por diversos fatores. Dentre eles pela forma que assume o aparelho 
de Estado, o regime político, a cultura pré-existente em relação aos mortos, e as necessidades psicológicas dos que perderam seus entes queridos, apenas para citar os fatores mais importantes. A forma e o conteúdo assumido por esses processos históricos, em especial no imediato pós-guerra, podem variar enormemente conforme cada sociedade e cada país. Reside neste aspecto a importância de se levar em conta os estudos sobre estes temas que tenham base internacional.

O culto cívico dos mortos remonta ao início da Época Contemporânea. Segundo a obra clássica de Ariès, os primeiros soldados mortos a serem homenageados com um túmulo comemorativo foram os caídos nas guerras civis da Revolução Francesa, com direito a monumento, capela expiatória e cemitério. (Ariès, 1982) A preocupação com a rememoração dos mortos contou com os diversos rituais de homenagens realizados pela Igreja Católica, que tinha consciência da necessidade de manter este culto.

A Primeira Guerra Mundial inaugura de forma sistemática esta tendência ao culto cívico dos mortos. É em 1920 que a Grã-Bretanha, por ter consciência que seria inviável trasladar todos os corpos de seus soldados mortos na Europa Continental para suas ilhas, toma uma decisão que foi seguida por outros países. Ao escolher as cinzas de um soldado desconhecido dentre os seus mais de 10.000 mortos nãoidentificados e levá-lo para a Catedral de Westminster, forneceu as bases para o culto ao soldado desconhecido em escala mundial. 
Em 1921, fica pronto o maior símbolo deste monumento ao soldado desconhecido, sob o Arco do Triunfo em Paris. Este monumento servirá de modelo para os demais mausoléus aos mortos desconhecidos, que de forma recorrente apresentarão o padrão arquitetônico dos arcos e também da presença da chama eterna em homenagem aos mortos.

A historiografia que debate a questão de como a sociedade se relaciona com a finitude da vida e com o tratamento que dispensa aos seus mortos revela aspectos da própria concepção de história de um povo. Para o historiador Jacques Le Goff o munumentum tende a especializar-se em dois sentidos: o primeiro enquanto obra comemorativa de arquitetura ou de escultura, como no exemplo do arco de triunfo, coluna, pórtico, etc. Um possível segundo sentido seria caracterizado pelo monumento funerário destinado a perpetuar a recordação de uma pessoa no domínio em que a memória é particularmente valorizada: a morte. (Le Goff, 1992)

Michel Vovelle entende os monumentos modernos funerários a partir da tendência dos mesmos no sentido da democratização e funcionalização da representação da morte para os interesses dos vivos. (Vovelle, 1987) Enquanto o período entre guerras assistiu o fenômeno da proliferação de monumentos aos mortos na Primeira Guerra Mundial, o Brasil não vivenciou esta experiência diretamente ${ }^{4}$.

${ }^{4}$ Existe o Mausoléu aos Mortos da DNOG no cemitério São João Batista no Rio de Janeiro de 1928, em referência aos brasileiros mortos durante a Primeira Guerra Mundial, entretanto a rememoração desse evento fracassou. 
Com um cenário em que a necessidade de sepultar os mortos e as homenagens aos mesmos eram frequentes, Vovelle identificou este período como o ciclo de nascimento, vida e morte do monumento "comemorativo". Esta tendência se encerraria no segundo pós-guerra com a anulação das fórmulas triunfalistas, com a construção de monumentos abstratos e mesmo de antimonumentos. (Vovelle, 1987)

Percebe-se, na utilização política dos monumentos fúnebres, que determinados aspectos podem ser enfatizados nos mesmos. A grande quantidade de placas comemorativas homenageando os mortos franceses em diversas guerras em Paris é impressionante.

Um aspecto interessante na maneira como esta morte é lembrada nestes monumentos é o discurso utilizado para transmitir esta informação. Nas já citadas placas espalhadas em Paris, percebe-se como a morte na guerra é rememorada. A inscrição nestas placas refere que os mortos são "Mort pour la France", ou seja, Mortos pela França. Tal expressão remete a uma maior dramaticidade ao evento que já é trágico, mas que utiliza a ideia de voluntarismo do indivíduo que foi morto pela França.

Pode se comparar estas placas que se referem aos monumentos fúnebres franceses com a ideia de que os soldados morreram por uma causa, qual seja, pela pátria francesa. Já se compararmos com a forma como os estadunidenses tratam seus mortos, este discurso se altera. Todos os cemitérios americanos ou placas que 
fazem alusão aos mortos em guerra destacam que naquela data o soldado foi morto, por vezes utilizando apenas as iniciais KIA (Killed in Action), ou seja, morto em ação. O protagonismo do soldado norte-americano é enfatizado na forma de se referir ao morto, que no caso é ativo: foi morto combatendo.

De toda forma, a tendência de se construir o Monumento Fúnebre em locais públicos tem a intenção de demonstrar o sentido patriótico e universal da morte do soldado. Muitos monumentos fúnebres são transferidos dos cemitérios para os locais públicos justamente para intensificar esta dimensão de sacrifício pelo coletivo.

Na Europa, depois da Primeira Guerra Mundial a tendência era construir cemitérios nos locais onde as batalhas mais sangrentas se desenrolaram ${ }^{5} \mathrm{Na}$ Segunda Guerra Mundial, a maior parte dos soldados foi enterrada em cemitérios construídos especificamente para este fim. Eram destinados para soldados que tombaram em batalha, que descansariam praticamente no mesmo local em que estas ocorreram.

A ênfase no uso do culto cívico aos mortos provocou diversas vezes este translado de restos mortais, sempre buscando proporcionar maior visibilidade ao evento ou alimentar comemorações e rememorações do mesmo. Nem sempre tal objetivo é alcançado, como demonstram os exemplos que examino a seguir. Geralmente

\footnotetext{
${ }^{5}$ Por exemplo o gigantesco cemitério de Verdun, ou o Ossuário de Douaumont.
} 
estas tentativas de destacar uma lembrança de um evento conferem significação aos monumentos, os quais são sempre (re)significados no presente (Loderlo e Lacerda, 2007).

Esta relação do presente com o passado por meio do monumento é marcada pela mediação da afetividade, da emoção. Certos momentos históricos permitem que determinadas lembranças sejam acionadas, como define Françoise Choay (Choay, 2001, p.18) A percepção de sacrifício em prol de uma causa justa está relacionada às cerimônias públicas que pretendem consolar os atingidos pela perda de seus entes queridos numa guerra.

O culto aos mortos faz parte deste rito de passagem, em que três fases podem ser identificadas. A separação, a margem e a incorporação (Gennep, 2011). Enquanto a separação do indivíduo do mundo dos vivos é realizada com o seu sepultamento, o rito agregador deste soldado ao mundo dos mortos e, correspondentemente, sua identificação com a figura do herói, ocorre nas cerimônias públicas de rememoração. No caso dos monumentos modernos esta relação se faz em torno da coletividade. São os heróis que são celebrados nas cerimônias.

Ao longo do tempo, as cerimônias se transformam, algumas se rotinizam e outras desaparecem. As mediações são necessárias para a decisão do que pode ou não ser comemorado e rememorado em relação aos mortos em guerra. O historiador americano Jay Winter cita o exemplo do final da Guerra do Vietnã que, para os 
Estados Unidos não pode ser comemorado, ao contrário do que ocorre, por exemplo, com o dia da Vitória para os franceses (Winter, 1999).

As memórias contestadas permeiam esta rememoração da guerra. Vários traumas interferem na categorização do que é comemorado, bem como o local onde tais cerimônias podem ser realizadas. Estes locais de memória ${ }^{6}$ são responsáveis por demarcar na memória os pontos de referência, não só para aqueles que sobreviveram a eventos traumáticos, mas também para aqueles que nasceram muito depois deles.

Percebe-se neste cenário a introdução de um novo léxico no culto funerário, religioso e patriótico:

[...] na guerra não se morre mas cai-se, a vida não se perde mas doa-se, não se desaparece mas vive-se eternamente, num acto de transfiguração da morte em heroísmo. A tradicional cruz dos cemitérios civis é substituída pela "Pedra da Lembrança", talhada em forma de altar, o "Altar da Pátria", para dar sentido a uma nova religião "laica", a uma nova liturgia baseada na sacralização do eterno sacrifício colectivo em nome da Nação ${ }^{7}$

\footnotetext{
${ }^{6}$ A partir da concepção presente na obra NORA, Pierre. Entre memória e história: a problemática dos lugares. Revista de Pesquisa Histórica. São Paulo,1993.

7 Trecho do verbete memoriais de guerra por HOWARTH, G. \& LEAMAN, O. Verbete Memoriais de Guerra In: Enciclopédia da Morte e da Arte de Morrer. Lisboa: Quimera Editores, 2001.p 346-347
} 


\section{MAUSOLÉUS AOS MORTOS EM COMBATE NO CASO BRASILEIRO}

No Brasil, esse culto cívico aos mortos em combate historicamente teve pouca ou nenhuma receptividade da sociedade em geral.

A maioria desses monumentos coletivos construídos no século XX para celebrar a memória institucional dos conflitos armados ocorridos entre o final da década de 1920 até 1982 estão localizados no Cemitério São João Batista no Rio de Janeiro.

A partir desse critério, o mausoléu da Revolta Tenentista de 1924 é um dos primeiros monumentos coletivos institucionais da Marinha ${ }^{8}$. Como é conhecida como a "Revolta esquecida" esse conflito engloba um movimento maior constante nos anos 20, o tenentismo. O Mausoléu foi igualmente esquecido. Os mortos do Couraçado São Paulo foram homenageados pelos seus colegas de marinha segundo o epitáfio do monumento. A imagem do couraçado está em destaque é uma réplica da medalha cunhada posteriormente. Não identifiquei em jornais da época manifestações e celebrações sobre esse evento ou esse monumento. Uma pesquisa mais específica pode revelar maiores detalhes sobre o mesmo.

Merece destaque a inscrição que já assimilava os termos usados nos memorias de guerra do período. Em primeiro lugar por utilizar a palavra vítima no lugar de mortos. Trata-se de operação simbólica destinada a ocultar a morte. |Em segundo

\footnotetext{
${ }^{8}$ São vários monumentos fúnebres coletivos da Marinha, destaco também a existência do Jazigo aos mortos na Revolta da Armada no Cemitério do Marui em Niterói (RJ)
} 
lugar, o ideal como motivo da morte. Os heróis tombaram por motivos nobres, não por ganho pessoal. Em terceiro lugar, a homenagem de seus companheiros, no caso a instituição militar prestando o culto cívico aos mortos. Aqueles que tombaram expressam valores caros à instituição.

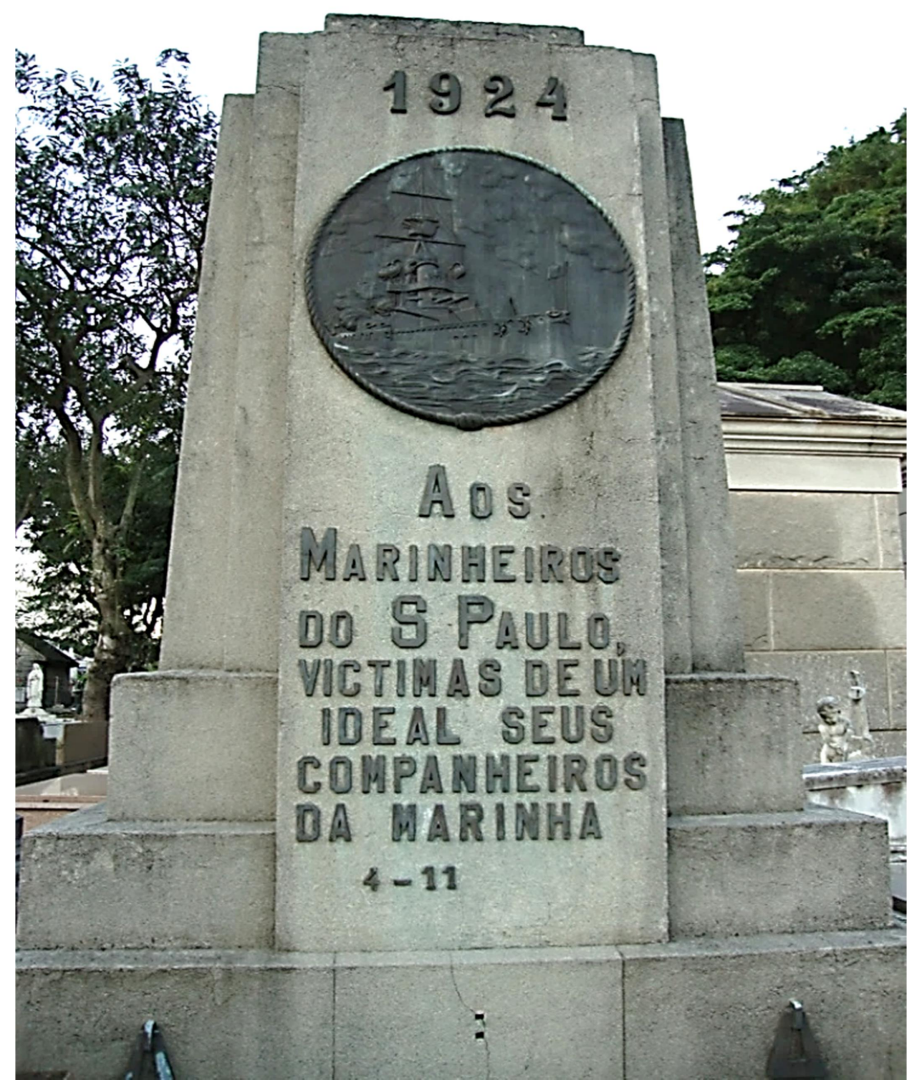

Figura 1. Mausoléu dos Marinheiros mortos em 1924 no Cemitério São João Batista no Rio de Janeiro (RJ). 
O Mausoléu aos Mortos do DNOG, inaugurado em 1928, conseguiu maior destaque na rememoração de seus mortos. Construído para abrigar os restos mortais de 156 brasileiros pertencentes da Divisão Naval de Operações de Guerra, o monumento localizado no Cemitério São João Batista no Rio de Janeiro celebra a participação brasileira nesse conflito mundial.

Diversos problemas foram enfrentados para formar este esforço de guerra. Falta de mão de obra qualificada, despreparo na organização, treinamento dos soldados, problemas na manutenção dos navios, etc. Praticamente nem chegando a combater de fato, as mortes foram provocadas pela gripe espanhola, responsável por significativo número de baixas na maioria dos exércitos envolvidos. Enterrados inicialmente no cemitério de Dakar no Senegal, foi determinado, no governo Arthur Bernardes em 1923, o repatriamento dos corpos. Os recursos para o transporte dos restos mortais e a construção do mausoléu só ocorreu em 1928, já no governo Washington Luís que abriu um crédito para as despesas.

O repatriamento desses combatentes da Marinha ocorreu dez anos depois de terminada a guerra. $\mathrm{O}$ translado possuía o intuito de dar ao luto um significado preciso às perdas singulares, obscurecendo a carência de sentido dessas mortes e da participação brasileira no evento. O objetivo era garantir aos 'heróis' anônimos um lugar na história, como é próprio do culto cívico dos mortos que se constitui na modernidade (Catroga, 1990, p.173). 
Neste mausoléu é possível identificar que a alegoria masculina traz na mão direita uma coroa de louros, enquanto com a mão esquerda ampara a outra figura masculina, segurando-a pela mão. Ambas têm o olhar voltado para baixo, numa postura que denota respeito aqueles ali sepultados.

A coletividade é exaltada nesse mausoléu. Os nomes dos indivíduos mortos não é mencionado, ao contrário, são os nomes das embarcações das quais eles faziam parte é que se destaca no interior do espaço.

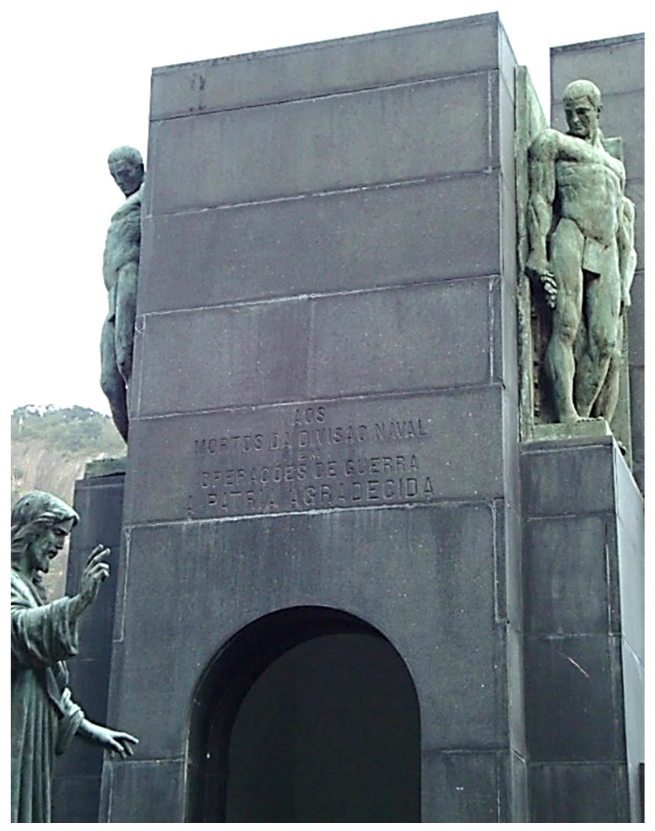

Figura 2. Mausoléu dos Mortos da DNOG.

Outro monumento que pode ser destacado nesse período é o Mausoléu dos mortos na Intentona Integralista de 1938, localizado no Cemitério São João Batista no 
Rio de Janeiro. Em 11 de maio de 1938, durante a tentativa de golpe integralista, 7 fuzileiros navais foram mortos na tentativa de resgate do Ministério da Marinha em poder dos revoltosos. Em mármore preto, seu formato lembra um navio. $\mathrm{O}$ túmulo coletivo possui além dos nomes dos fuzileiros mortos, uma coroa de louros estilizadas artificiais (como no padrão que pode ser encontrado na Europa até hoje) e a escultura de um fuzileiro naval simbolizando a figura de um sentinela do túmulo.

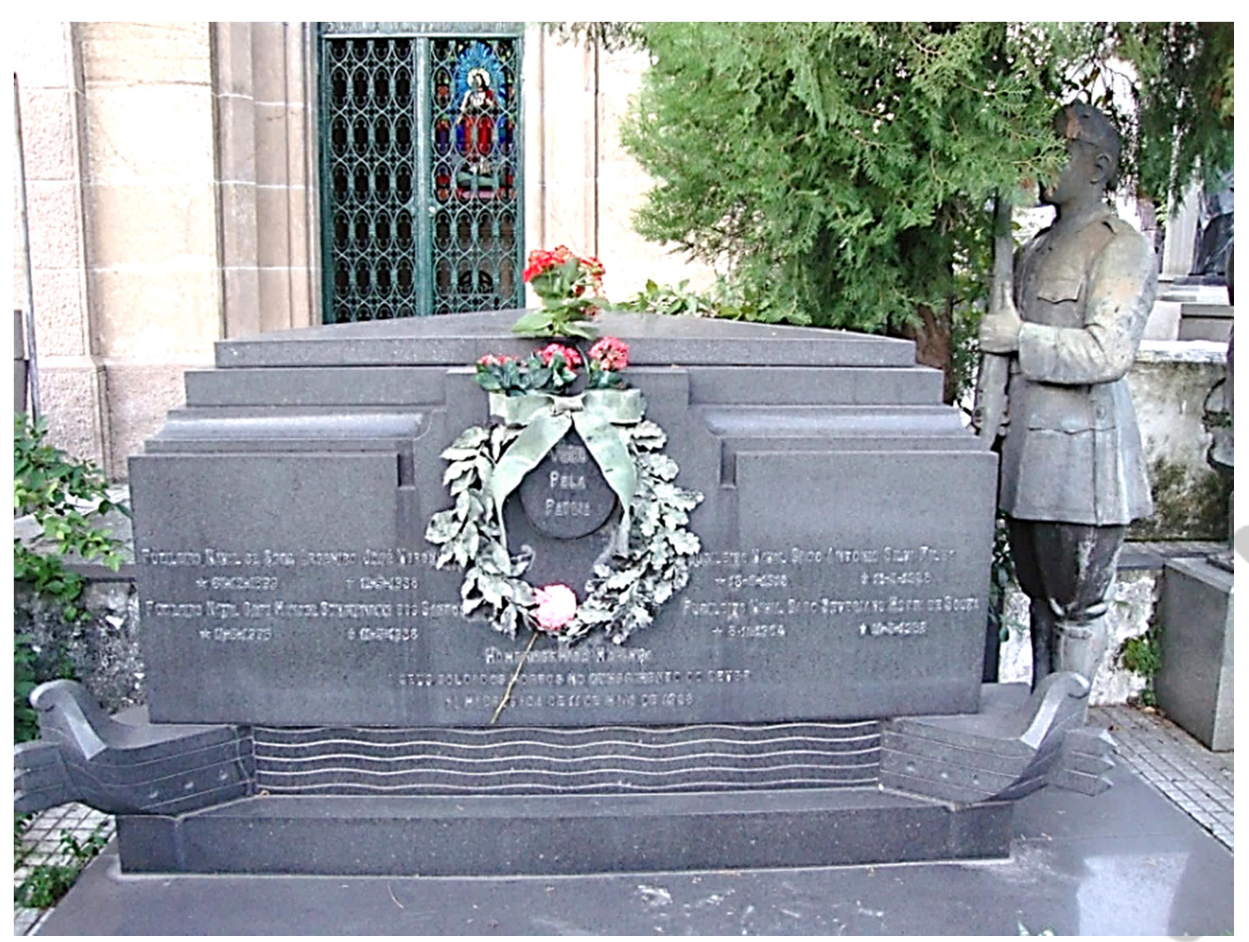

Figura 3. Mausoléu dos mortos na Intentona Integralista de 1938. 
O interessante sobre esse monumento é que o mesmo foi patrocinado pelo Exército. Na frente do jazigo consta uma coroa de flores estilizada, em bronze. Essa coroa aparece na figura 3. No centro da coroa está a inscrição Tudo pela Pátria. A coroa possui do lado direito folhas de louro, que tem referência ao triunfo, à vitória. E do lado esquerdo, as folhas são de carvalho, que representam a força moral e física. Tais simbolismos foram incluídos para reforçar a narrativa do túmulo, de que os fuzileiros mortos venceram, irão para o paraíso, e sua força moral é que resistiram pelo bom combate, defenderam a pátria de traidores.

Outros mausoléus coletivos que merecem ser apontados são os dois Mausoléus dos Aviadores, o antigo de 1941 e o novo de 1957. Ambos estão localizados no Cemitério São João Batista no Rio de Janeiro e são de autoria da mesma escultora, Celita Vaccani ${ }^{9}$. Nas duas obras é possível identificar como os elementos cívicos e de ligação à instituição aeronáutica são priorizados.

No túmulo "antigo" a inscrição no alto destaca a frase "A glória pelo dever". O conjunto escultórico destaca a presença de aviões e enfatiza a questão do trabalho realizado nas alturas.

Essa mesma artista participou de outros concursos militares e hoje é possível encontrar muitas de suas esculturas no Campo dos Aphonsos no Rio de Janeiro.

\footnotetext{
${ }^{9}$ HÖFKE, Tathyane Ferreir. As motivações temáticas de Celita Vaccani, nos Mausoléus dos Aviadores Militares. Dissertação de Mestrado, UFRJ, Ano de Obtenção: 2007.
} 
Como por exemplo a placa com a face de Jean Mermoz, Monumento a Mermoz, situado na cabeceira da pista deste espaço da Aeronáutica.

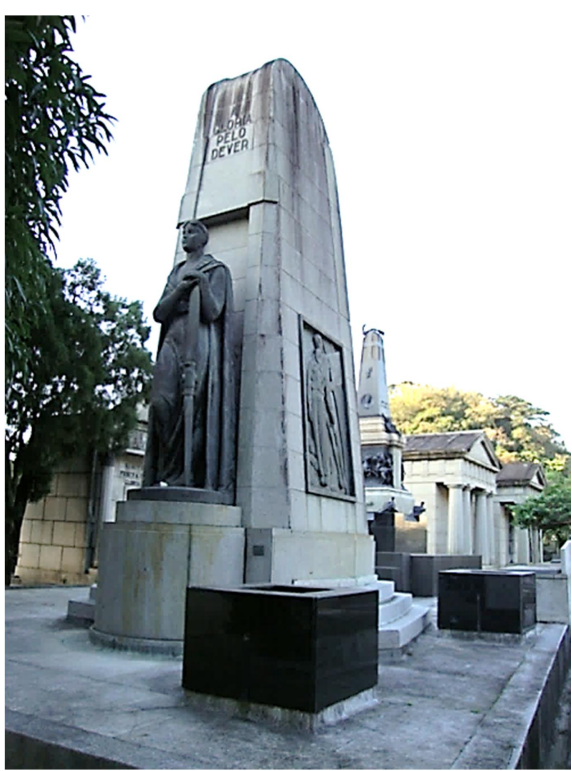

Figura 4. Mausoléu dos Aviadores, o Antigo.

Concebido pela escultora Celita Vaccani em 1957 e finalizado em 1959, o mausoléu dos Aviadores "Novo", possui o título de Pantheon dos Heróis. Já a partir da entrada é possível perceber esta ênfase no espaço como local de repouso dos restos mortais de "heróis". A frase no alto do pórtico de entrada é "Do espaço para a glória" e possui em destaque o símbolo da Aeronáutica, algo que no primeiro monumento não havia, já que a própria Aeronáutica não havia ainda sido criada. Esse monumento tem linhas mais modernas e esculturas abstratas, condizentes com os aspectos das artes plásticas do período. 


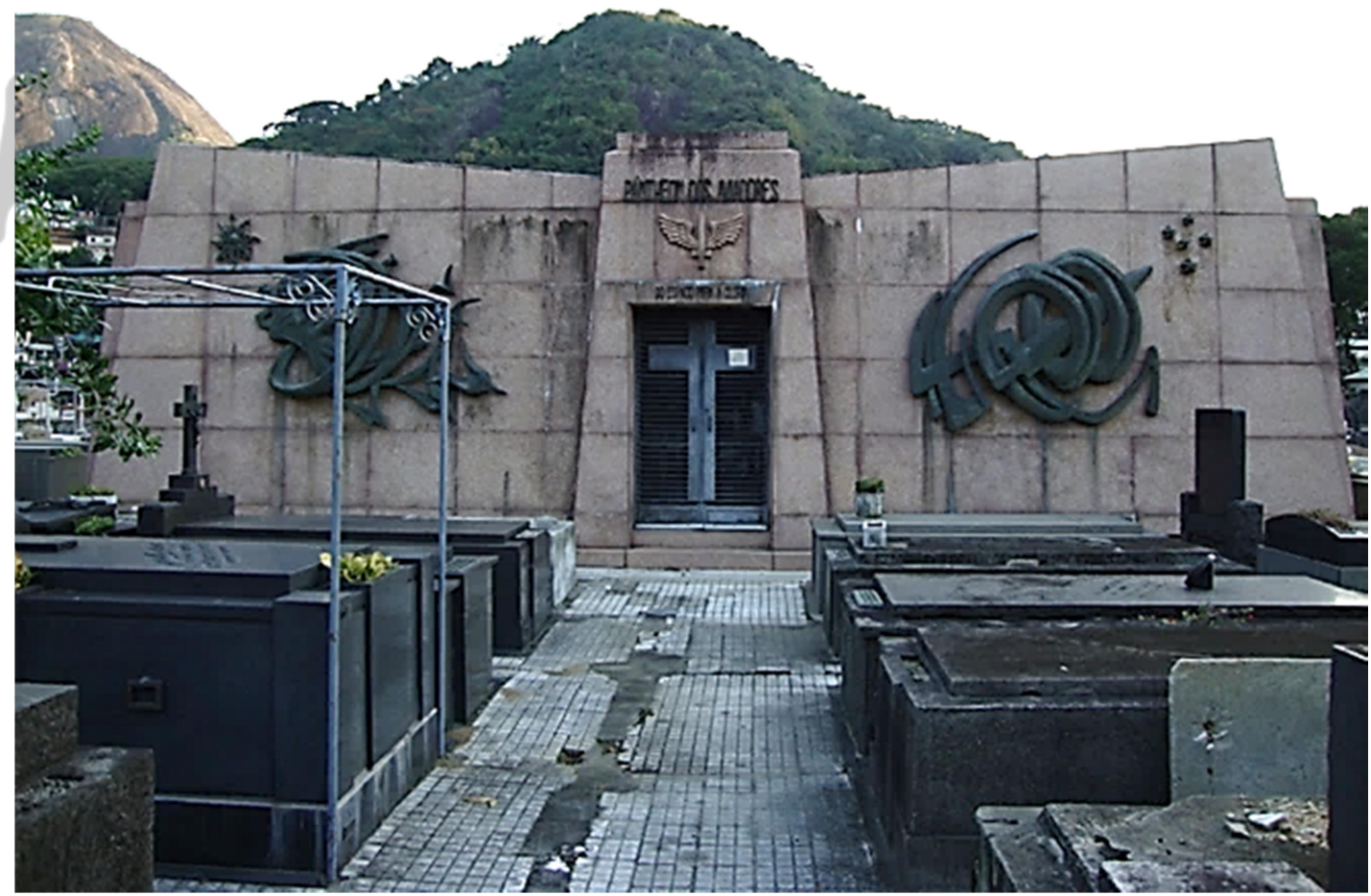

Figura 5. Mausoléu dos Aviadores, o Novo.

\section{CONCLUSÕES}

A partir da análise desses exemplares de mausoléus coletivos militares localizados no Cemitério São João Batista no Rio de Janeiro, percebe-se como o engajamento desses indivíduos não foi encerrado com sua morte.

Ao contrário, a negação da individualidade presente nesses jazigos demonstra como a identidade militar é o fator privilegiado nessa rememoração. Os nomes 
dos mortos, quando não estão ocultos são deixados em segundo plano. A padronização das carneiras também é outro fator que impede qualquer tentativa de personalização desse espaço.

A instituição que é rememorada em cada um desses mausoléus, a narrativa divulgada nesses monumentos é a escolhida pela instituição.

$\mathrm{O}$ que se percebe é que nenhum desses monumentos logrou agregar de forma permanente a população aos ritos de rememoração dos mortos nesses conflitos. Passado um período inicial de relevância, logo se viam esquecidos e abandonados.

Muito difundido na Europa, o culto cívico dos mortos não obteve o mesmo apelo no Brasil. Segundo Fernando Catroga, a memória liga os indivíduos verticalmente, a grupos e entidades, e horizontalmente "a uma vivência encadeada do tempo (subjetivo e social), submetendo-os a uma 'filiação escatológica' garantida pela reprodução (sexual e histórica) das gerações e por um impulso de sobrevivência, nem que seja na memória dos vivos" (Catroga, 2009, p.25). Essa articulação fracassou no Brasil. Tais monumentos e cerimônias não conseguiram exercer a função social para a qual foram concebidos. 


\section{REFERÊNCIAS BIBLIOGRÁFICAS}

ARIÈS, P. O Homem diante da morte Tradução de Luiz Ribeiro. V. 2. Rio de Janeiro: Francisco Alves, 1982.

CATROGA, Fernando. O céu da memória: cemitério romântico e culto cívico dos mortos. Coimbra: Minerva, 1990.

. Os passos do homem como restolho do tempo: memória e fim do fim da história. Coimbra: Almedina, 2009, p.25

CHOAY, Françoise. A alegoria do Patrimônio, São Paulo: UNESP, 2001.

CREVELD, Martin Van, The culture of War. New York: Ballantines Books, 2008.

GENNEP, Arnold van. Os ritos de passagem. Petrópolis: Vozes, 2011.

KOSELLECK, Reinhart. Uma história dos conceitos: problemas teóricos e práticos. Estudos Históricos, Rio de Janeiro, v.5, n.10, 1992.

LE GOFF, Jacques. Documento/Monumento. In: LE GOFF, Jacques. História e memória. São Paulo: Unicamp, 1992.

LORDELO, E.; LACERDA, M. Os monumentos e sua reprodutibilidade: mídias e valores. RISCO. Revista de pesquisa em arquitetura e urbanismo. Programa de PósGraduação do Departamento de Arquitetura e Urbanismo EESC-USP, 6 [2], 2007.

RÜSEN, Jörn. Como dar sentido ao passado: questões relevantes de meta-história In: História da historiografia, Ouro Preto: Edufop, número 02, março 2009.

VOVELLE, Michel. Ideologias e Mentalidades. São Paulo: Brasiliense, 1987. 
WINTER, Jay; SIVAN, E. War and Remembrance in the twentieth century. Cambridge University Press, 1999.

NORA, Pierre. Entre memória e história: a problemática dos lugares. Revista de Pesquisa Histórica. São Paulo,1993.

HOWARTH, G.; LEAMAN, O. Verbete Memoriais de Guerra In: Enciclopédia da Morte e da Arte de Morrer. Lisboa: Quimera Editores, 2001.p 346-347 